\title{
Comparative analysis of the state of Pinus sylvestris L. and Pinus koraiensis Siebold et Zucc. in the Vladivostok agglomeration
}

\author{
N.G. Rozlomiy ${ }^{1}$, and A.N. Belov ${ }^{2}$ \\ ${ }^{1}$ Primorskaya State Academy of Agriculture Forestry Institute, 44 Bluhera st., 692510 Ussuriisk, \\ Russian Federation \\ ${ }^{2}$ Far Eastern Federal University FEFU, School of Education, Department of natural science education \\ Ajax 10, 690922 Vladivostok, Russia
}

\begin{abstract}
The paper analyzes the growth of Pinus sylvestris L. and Pinus koraiensis Siebold et Zucc. Bonitet, age, diameter and height, density and resources were determined on 11 sample plots. The analysis of the state of artificial plantations of pinus koraiensis and pinus sylvestris, planted from 1954 to 1980 , indicates their low preservation, which after 25-40 years, depending on the location of the research object, decreases to $14-25 \%$, which confirms the need for expanding and reconstruction of green areas of the cities of the "Big Vladivostok". The main reasons for the decline in the preservation of plantations are forest fires and unauthorized felling.
\end{abstract}

\section{Introduction}

The forest cover of the Far East is very high. The forests of the Far East (FE) of Russia contain from 3 to $16 \%$ of the area, timber reserves, biological diversity of this form of vegetation cover. On the territory of the Far East, there are 144 species of trees, 224 species of shrubs and 26 species of woody lianas, 57 dwarf shrubs, 23 dwarf shrubs, more than 2700 species of grasses. Nut - 14 species, berry - 121, vegetable - 200, juice - 28, melliferous and pergoniferous - 250, essential oil - 144, medicinal - more than 1000 species (Vascular plants of the Soviet Far East, Vol. 1-8, 1985-1996; Tagiltsev, 2004).

About 20 billion $\mathrm{m}^{3}$ of timber is concentrated here, about 274 million hectares are occupied by forests, which is about $29 \%$ of forest reserves and $46 \%$ of the entire forest territory of Russia (Analysis of statistical reference data of DalNIILKh, 2015). However, over the past 20 years, the infrastructure for forest protection and restoration has been lost, which affects, first of all, timber resources, especially valuable species, and leads to a partial loss of such important non-timber forest resources as wild vegetables, berries, mushrooms, furs, honey.As a result, the sustainable development of precisely forest-surplus regionsbecomes impossible. In the Far East, according to V.M. Urusova (2007), 70\% of timber is received from clear felling, selective felling- $20 \%$, and the structure and composition of the region's forests require the predominance of selective felling - they should yield $40-45 \%$ of timber with $30-40 \%$ of timber from clear felling and $10-30 \%-$ from gradualfelling. 
In order to restore and diversify the forest fund in the Primorsky Krai, to determine the possibility of obtaining various wood in a short time and the possibility of switching to mass planting of crops, monocultures of Juglans mandshurica Maxim., Fraxinus mandshurica Rupr., Phellodendron amurense Rupr., Populus maximowiczii A. Henry, Pinus koraiensis and Pinus sylvestris were created on the territory of the state forest fund since the beginning of the 1950s. Since1950-70s, on the territory of the forestries of Primorsky Krai, the main introduced species was Pinus sylvestris, which was massively planted in the late 1960s and early 1970s. The condition of this species on the territory of the Vladivostok forestryas a whole, as well as in the Primorsky Krai, is unsatisfactory (Belov A.N. et al 2020). Therefore, in the 1970s, the scientific community decided not to create forest cultures of non-zoned species. Most of the plantations were made in the border area in order to create fire strips to prevent the passage of transboundary fires across the state border of the Russian Federation.

\section{Research methods and objects}

The work was carried out in 2006-2018. The object of research was the green zone of Vladivostok and Ussuriysk, namely, plantations of artificial origin Pinus sylvestris, Pinus koraiensis (cedar) established by the Vladivostok forestry and the Ussuriysky district forestry (the former Ussuriysky forestry of the Primorsky forest management) in the 1950s. To analyze the growth of tree species in the green zone of the cities of the Vladivostok agglomeration, 11 sample plots were laid according to the method of I.A. Pavlenko (Pavlenko, 1988).

The laying of sample plots was preceded by route studies. Their goal was to reveal the patterns of placement of artificially created plantations, their confinement to certain elements of the relief, preservation, taxational specifications, features of growth and development.

The areas of plantations for each tree species selected for research were chosen from the book "Accounting for forest cultures". The year of production of forest crops, the method of planting, the type of planting material, and the peculiarities of agrotechnical care were found out.

The size of the sample plots ranged from 0.4 to 1 hectare or more, so that in each area the number of trees of the main species was at least 200 pieces.

\section{Research results}

To analyze the growth of crops of various tree species, 11 sample plots were laid within the green zones of the cities of the "Big Vladivostok".

Pinus koraiensis (cedar) - crops were created on the territory of the Ussuriysk urban district in the 1980s - 90s, their total area is 43 hectares (Table 1).

Table 1. Taxationalspecifications of sample plots with Pinus koraiensis crops

\begin{tabular}{|l|l|l|l|l|l|l|l|}
\hline No. & Content & Bonitet & $\begin{array}{l}\text { Age, } \\
\text { years }\end{array}$ & D, cm & Hav, m & Density & $\begin{array}{l}\text { Resources, } \\
\mathrm{m}^{3} / \mathrm{ha}\end{array}$ \\
\hline 1 & 2 & 3 & 4 & 5 & 6 & 7 & 9 \\
\hline 1 & $10 \mathrm{~K}$ & II & 20 & 8.0 & 4.0 & 0.3 & 2.1 \\
\hline 2 & $10 \mathrm{~K}$ & II & 30 & 10.0 & 5.0 & 0.3 & \\
\hline 3 & $10 \mathrm{~K}$ & III & 37 & 10.0 & 6.3 & 0.4 & \\
\hline 4 & $10 \mathrm{~K}$ & III & 40 & 12.0 & 6.3 & 0.4 & \\
\hline 5 & $10 \mathrm{~K}$ & II & 21 & 8.0 & 4.2 & 0.3 & \\
\hline
\end{tabular}


From 1959 to 2001, forest areas with Pinus koraiensis in the Primorsky Krai decreased by $33.6 \%$. Over the past 100 years, the range of Pinus koraiensis has become fragmented, and its population structure has been disrupted. Part of the gene pool in the form of highly productive plantations of cedar has been irretrievably lost, since this species has been the main object of logging for a long time. Primorsky Krai has 3 forest seed areas.Therefore, at least 9 genetic reserves should be allocated on its territory, but not a single reserve exists in Primorye yet (Orekhova, 2012).

Pinus sylvestris - the first coniferous introduced species in Primorye. At the end of the 19th - beginning of the 20th century, under the Nikolskoye forestry, there was the Priamurskaya lower forest school, which prepared its pupils for the execution of lower positions in the forestry department - overseers, surveyors, forest guards. The school went down in history by the fact thatin 1900, under the leadership of the forester N.S. Bogolyubov, pupils planted a pine grove with an area of 1.7 hectares in the region of the Kamenushka village(former P'yankov Zavod tract) (Urusov, 1977). According to B.P. Kolesnikov (1946) and V.M. Urusov (1977), in Barsukovskaya Grove (as these cultures began to be called), the plantation spots were located in the corners of squares with a side of 1 fathom: there were originally 75 rowsfrom north to south, from east to west -50 .

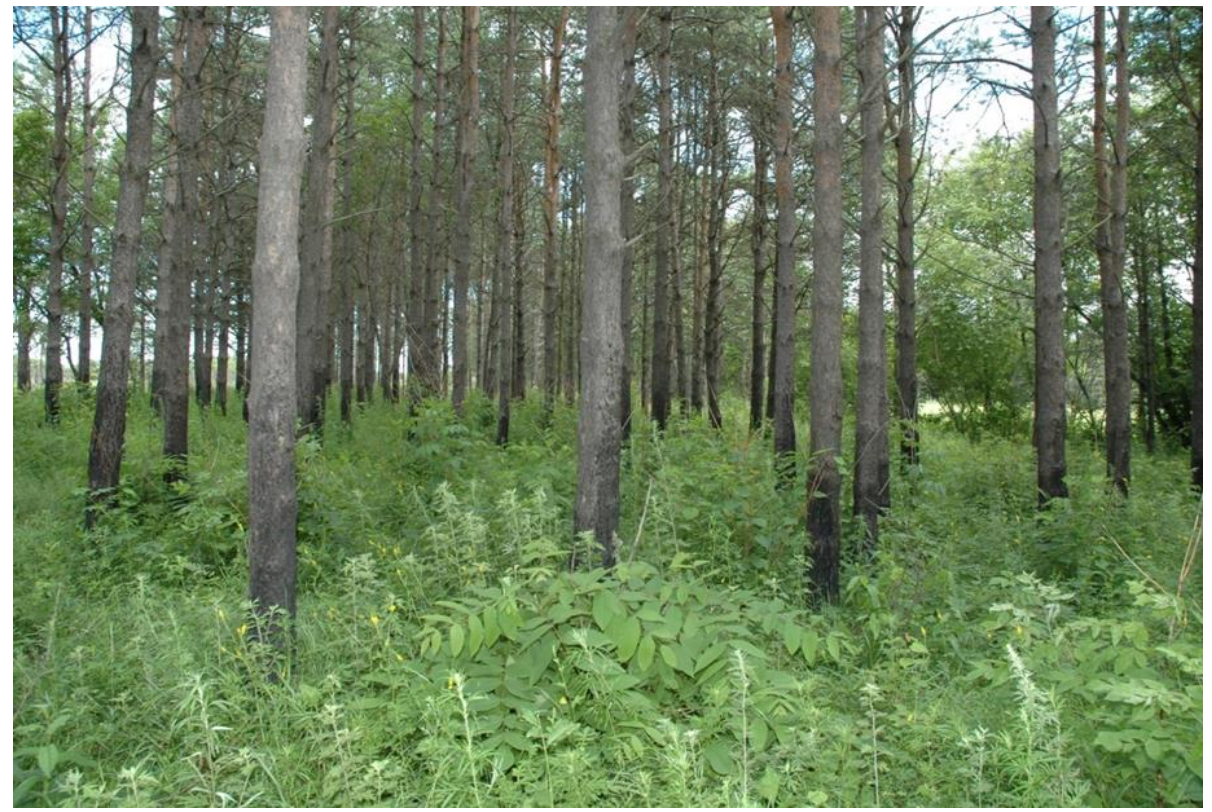

Fig. 1. Monoculturesof Pinus sylvestris (Kamenushka village)

Over the entire area of 1.7 hectares, 3750 seedlings were placed (2200 pieces per hectare) (Figure 1). In the 60s of the twentieth century, this territory became part of the Educational and Experimental Forestry Enterprise of the Primorsky Agricultural Institute, where students of the forestry faculty annually underwent educational practices in various disciplines - forestry, taxation, forest crops, phytopathology and others.

There was a summer pioneer camp near the pine grove, and the pine grove was constantly filled with people (Figure 2). The growth of pinus was characterized by quality class I with the accumulation of more than $500 \mathrm{~m}$ of the total timber resources (V.M. Urusov indicates $660 \mathrm{~m} \mathrm{ha}$ ), while every fourth tree had various defects, i.e. technical failure rate reached $25 \%$. At the age of $60-80$ (age class IV, this is a middle-aged plantationfor a pinus), almost all of its trees have already been damaged by various wood- 
destroying fungi, many of them were sick, and there were completely dried pinus trees (Rozlomiy 2011; Rozlomiy 2014).

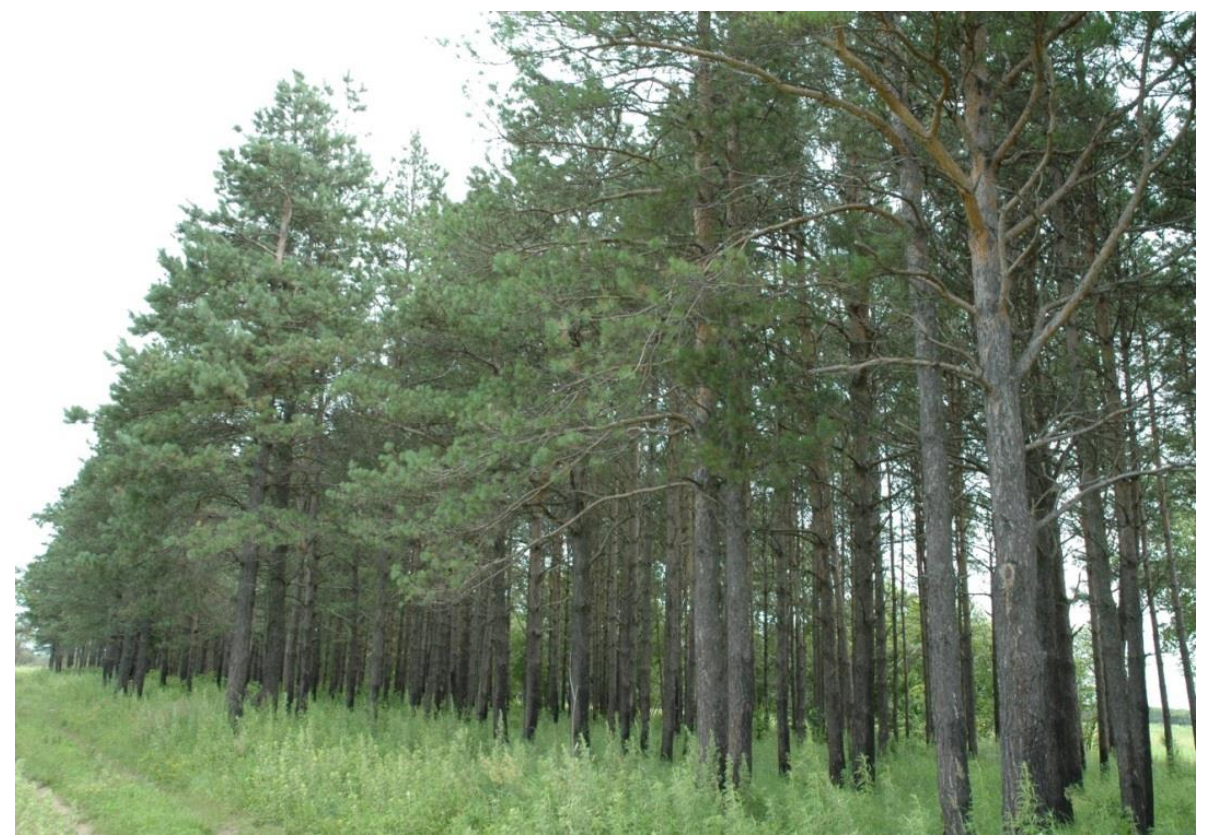

Fig. 2. Monoculturesof Pinus sylvestris (Dubovyy Klyuch village)

Existing crops of this type were created in the late 1970s - early 1980s, their total area is 21.9 hectares (Table 2).

Table 2. Taxational specificationsof sample plots with artificially created plantations of Pinus sylvestris

\begin{tabular}{|l|l|l|l|l|l|l|l|l|}
\hline No. & $\begin{array}{l}\text { Conte } \\
\text { nt }\end{array}$ & Bonitet & $\begin{array}{l}\text { Age, } \\
\text { years }\end{array}$ & D, cm & $\begin{array}{l}\text { Hav, } \\
\mathrm{m}\end{array}$ & Density & $\begin{array}{l}\text { Resource } \\
\text { s, } \\
\mathrm{m}^{3} / \mathrm{ha}\end{array}$ & No. \\
\hline 1 & 2 & 3 & 4 & 5 & 6 & 7 & 8 & 9 \\
\hline 1 & $10 \mathrm{~S}$ & 1 & 37 & 24.9 & 16.0 & 0.6 & 8.2 & 72 \\
\hline 2 & $10 \mathrm{~S}$ & 3 & 26 & 18.8 & 8.6 & 0.5 & 36.4 & - \\
\hline 3 & $5 \mathrm{~S} 5 \mathrm{Ya}$ & 1 & 29 & 21.1 & 12.2 & 0.6 & 38.3 & - \\
\hline 4 & $10 \mathrm{~S}$ & 1 & 36 & 22 & 15.0 & 0.6 & 22.6 & 72 \\
\hline 5 & $8 \mathrm{~S} 2 \mathrm{D}$ & 2 & 33 & 22.5 & 10.5 & 0.5 & 24.1 & - \\
\hline 6 & $10 \mathrm{~S}$ & 3 & 30 & 22.0 & 8.0 & 0.6 & 29.7 & - \\
\hline
\end{tabular}

\section{Research results}

The analysis of the state of artificial plantations of Pinus koraiensis and Pinus sylvestris, planted from 1954 to 1980, indicates their low preservation, which after 25-40 years, depending on the location of the research object, decreases to $14-25 \%$, which confirms the need for expanding and reconstruction of green areas of the cities of the "Big Vladivostok". The main reasons for the decline in the preservation of plantations are forest fires and unauthorized felling. Phyto- and entomological conditions, general condition and growth are satisfactory (Figure 3). 


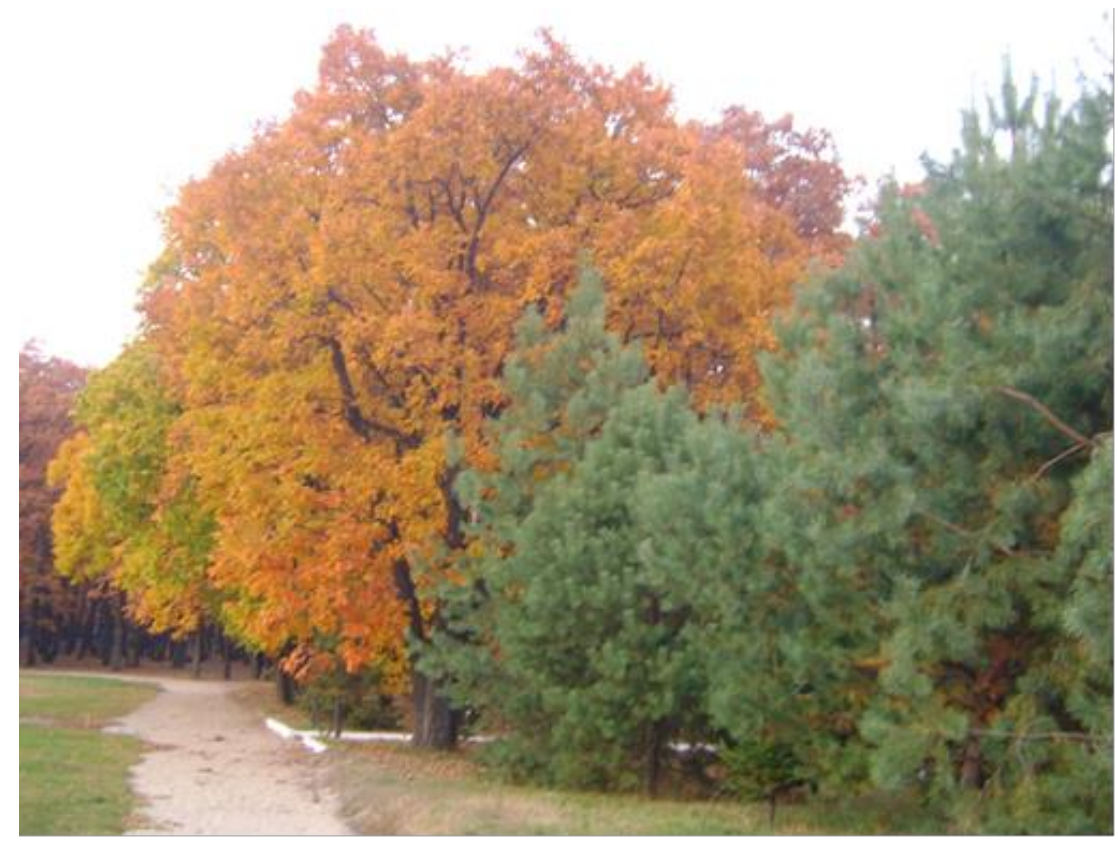

Fig. 3. Speciesof Pinus sylvestris (plantedin 1980s - 1990s)

It should be noted that there is almost no undergrowth in the forest plantations located in the immediate vicinity of cities $(3-5 \mathrm{~km})$. Initially, in the first age class, the plantings grow according to the III class of bonitet. With further growth, the bonitet rises to II and I classes. The analysis of the course of growth of the studied tree species growing in different geobiological conditions indicates a high energy of their growth for all taxation indicators.Therefore, these species can be recommended for creating an ecologically sustainable green belt.

\section{References}

1. A.N. Belov, S.A. Bersenyova, O.N. Ivus, G.A. Belova, Systematic Reviews in Pharmacy, 11(3), 538 (2020)

2. B.P. Kolesnikov, Materials on the history of flora and vegetation of the USSR, 2, 321 (1946)

3. T.P. Orekhova, Coniferous boreal zones, 30(3-4), 298 (2012)

4. N.G. Roslomiy, G.V. Gukov, Bulletin of IrGSKhA, 44-2, 133 (2011)

5. N.G. Roslomiy, M.S. Titova, G.V. Gukov, Bulletin of BSAU, 2(30), 93 (2014)

6. Vascular plants of the Soviet Far East, ed. S.S. Kharkevich, 1985-1996

7. Yu. G. Tagiltsev, R.D. Kolesnikova, A.A. Nechaev, Far Eastern plants - our doctor, 520 (2004)

8. V.M. Urusov, L.M. Yagodina, Natural flora of the Far East, 87 (1977)

9. V.M. Urusov, I.I. Lobanova, L.I. Varchenko, Conifers of the Russian Far East valuable objects of study, protection, breeding and use, 438 (2007) 